\title{
The relationship between the arts and medicine
}

P Anne Scott University of Stirling

\begin{abstract}
In this paper some of the intriguing links between the arts and medicine are explored. As a starting point I consider the notion of whole person understanding as articulated by Downie in an article entitled

"Literature and medicine", published in the Journal of Medical Ethics in 1991. ${ }^{1}$ I suggest that the arts can contribute to whole person understanding in at least three ways. The arts may stimulate: (a) insight into common patterns of response (shared human experiences); (b) insight into individual difference or uniqueness, and (c) enrichment of the language and thought of the practitioner.

Much literature which explores the relationship between the arts and medicine tends to focus on the value of the arts in increasing our understanding of the particular individual, "whole person understanding" in Downie's sense of the word. This, however, assumes that "whole person understanding" should focus only on the unique in the individual. This view is, I think, mistaken. If we take the notion of "whole person" seriously then we must recognise that which is unique but also that which humans may share. I suggest that this broader view is of the greatest importance in any consideration of the relationship between the arts and medicine.

(F Med Ethics: Medical Humanities 2000;26:3-8)

Keywords: Arts; literature; medicine; humane practice
\end{abstract}

\section{Introduction}

My initial interest in the links between the arts and medicine derived from an examination of various approaches to teaching ethics to undergraduate nursing and medical students. While examining the literature on the teaching of health care ethics, I began to discover a difference in the pattern of approach between the United Kingdom (UK) and the United States of America(USA). Within the UK when ethics was taught in nursing or medical programmes a professional philosopher and/or a hospital chaplain was engaged to teach a specified number of sessions, usually on topics such as abortion, assisted reproduction, euthanasia and the ethics of transplants. Such programmes were becoming increasingly sophisticated and might also include some sessions on Kantian duty-based moral theory and Utilitarianism. In the late 1980s when Kenneth Boyd was completing The Pond Report, ${ }^{2}$ all ethics teaching in medical curricula in the UK was on an elective basis. The United Kingdom Central Council for Nursing, Midwifery and Health Visiting (UKCC) had gone much further by insisting that in the development of new nursing and midwifery programmes a certain number of contact hours must be spent on professional, ethical and legal issues in nursing. ${ }^{3}$

However, in the USA increasingly the teaching of ethics, particularly to medical students, tended to be embedded in more broad-based medical humanities programmes which included history, law, and the arts (with a particular focus on literature) as well as philosophical ethics.

Why turn to the arts in medical or nursing education? Surely there is already enough in these respective curricula without demanding even more content be added and absorbed? Perhaps so. Indeed, when I began to use literature and film in my teaching of health care ethics, initially I did it for the simple reason that this seemed to be a more effective way to help students identify and consider ethical issues.

In essence I used this material as part of a consciousness raising activity. Use of literature or film brought certain issues into sharp focus, making them more alive for students. Students were presented with characters, some of whom they immediately identified with, such as the student nurse portrayed near the beginning of Whose Life

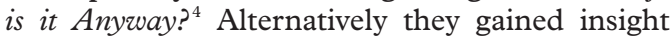
into the perspective, pain and frustration of a character like Ken Harrison, who in the normal course of events could easily be labelled a troublesome, uncooperative patient whom staff might endeavour to avoid. The arts - drama, short story, or a poem-might be used, in Alan Bennett's poignant phrase, to highlight the "casual cruelties routine inflicts". ${ }^{5}$

In her book Heroism as a Nursing Value ${ }^{6}$ Vassiliki Lanara draws attention to the influence which classical Greek Literature had on the development of nursing and particularly on the development of nursing's focus on holistic patient care. From my 
first contact with nursing I was brought up on a diet which emphasised (a) the vocational influence of the religious orders with its elevation of service and obedience, and (b) the army influence, again focusing on service, obedience and adding discipline. In 20th century versions of nursing history the most prominent character in the development of nursing in Ireland and the UK is Florence Nightingale. Thus Lanara's emphasis on the impact of early Greek literature provided an entirely new insight into nursing's historical evolution.

Lanara's argument supports the claim of Eric Cassell (in his classic work, The Place of the Humanities in Medicine ${ }^{7}$ ) that the humanities have always been part of medicine. Cassell goes on to state:

"They (the humanities) will play an increasingly important, necessary and specific role as medicine evolves beyond its present romance with technology towards a more balanced view of the origin and treatment of illness." 8

Perhaps Cassell is right at least to the extent that the humanities will be increasingly important for medical and health care education. There is a growing interest in this area around the UK. This is evidenced for example in the development of the Centre for the Arts and Humanities in Health and Medicine at the University of Durham. New medical curricula appear to leave open the possibility of a strong humanities influence in undergraduate medical education. ${ }^{9}$ There are also a number of nursing programmes that include elements of the humanities as part of the core curriculum. ${ }^{10}$

\section{Why the humanities?}

However, it does need to be asked why we should applaud a swing to increased humanities input in health professionals' education. Perhaps we may take as a starting point for this discussion a paper by Downie entitled "Literature and medicine". ${ }^{1}$ In this article Professor Downie suggests that there are four types of connection between literature and medicine. One type of connection benefits literature; another provides entertainment value; a third type potentially provides insight to the various professions regarding how they stand in the public perception; and finally a fourth type can be helpful to the practice of medicine (and, I suggest, nursing) by providing glimpses of what Downie terms "whole person understanding".

Downie points out that many authors and poets, indeed some who have made significant contributions, were also medical doctors, for example Dante and Chekhov. A number of these have brought to their literary works the insights which the practice of medicine provides. Illness, disease and the medical context also provide the mixture of emotion, drama, irony, humour, blood and gore which is grist to the mill of the novel, play, film and indeed TV serial. They are also meat and drink for the artist.

\section{Public stereotype}

It is within a similar context that insight may be gained in terms of the public stereotype and standing of various professional groups. Indeed there are a number of glimpses of different approaches to the practitioner-patient relationship in films such as Passionfish ${ }^{11}$ and Whose Life is it Anyway? ${ }^{4}$ I have found that the presentation of clips from these two films generates considerably more discussion, and seems to leave a much stronger impression, than simply suggesting that students read and discuss the models of professional-patient relationships described in Szasz and Hollander ${ }^{12}$ Veatch ${ }^{13}$ or Morse. ${ }^{14}$ Such insights into particular approaches to that relationship are probably of general interest to professional bodies; beyond this they are of direct interest to the neophyte practitioner attempting to find useful role models for practice.

It is the fourth type of connection between the arts and medicine, discussed by Downie, ${ }^{1}$ which interests me in particular. Downie argues that it is this connection which illuminates what he refers to as the "whole person approach" to medical practice. He contrasts the whole person approach with the scientific approach to medicine. The latter, he suggests, sees medicine's concerns as focused on general patterns, order and uniformity.

Downie goes on to suggest that one of the recognised strengths of medicine is its science orientation: the attempt to move between observation of patterns, hypothesis testing and theory (or model) development regarding the causes and potential treatments for disease. The primary focus is on the body, body systems and general patterns of disease and response. This focus is useful, necessary, and has brought important advances in diagnosis and in chemotherapeutic and surgical intervention. However, Downie claims that this approach, while valid and clearly useful, is insufficient. While the focus is on the general pattern, the specific need and particularity of the individual patient is in constant danger of being missed. Greenhaugh and Hurwitz ${ }^{15}$ provide a number of useful examples of this supposedly reductionist type of practice. (There is an interesting debate to be undertaken regarding the accuracy of describing medical science as reductionist. It might be argued to the contrary that 
medical research is in fact largely systems-based and therefore holist in the classic social science sense of this term. ${ }^{16}$ However, this debate is for another day.)

For the purposes of our present discussion let us grant that Downie is correct in his claim, that because of the focus on general patterns of disease and response in medical science and practice, the specific need and particularity of the individual patient is in constant danger of being missed. Downie argues that "whole person understanding" requires two things: (i) knowledge of the person's biography (or extended case history), and (ii) some imaginative sympathy with that biography.

He argues that the disciplines which develop and extend whole person understanding are "history and literature in all its aspects... . The humanities rather than the social sciences, are concerned with the particularity of situations and with their meaning and that concern is the way to whole person understanding." 17

\section{Whole person understanding}

It seems apposite at this point to consider why one would want "whole person understanding" in medicine or nursing. I suggest that nurses have never found dealing only with general patterns of response as easy as Downie seems to suggest - as it were in some sense divorcing the mind from the body and dealing only with the physical. Despite our current literature's many references to the ills of the task-allocation method of organising nursing work, ${ }^{18}$ the notion of providing comfort and care has permeated the nursing approach - at least in terms of rhetoric and education. The notion of comfort and care has traditionally been articulated in terms that made the psychosocial and spiritual dimension of patient care explicit For example, in the development of nursing research over the past 20 years, one sees a clear shift in the USA, Australia, and the UK. This shift is away from the traditional scientific research methodology, found in medicine and social science, to more narrative-based methodologies such as grounded theory, ${ }^{19}$ phenomenology ${ }^{20}$ and hermeneutics. ${ }^{21}$ The move indicates clear attempts by nurse researchers and scholars to recognise and learn from individual patients, regarding their particular experience and perceptions of illness, disease and treatment.

However, why is this particularisation of the illness experience thought necessary in the education of health care practitioners? The answer is, in many ways, quite straightforward. Practitioners are daily confronted with complex individuals who may be experiencing significant anxiety, vul- nerability and fear, because of some real or imagined disease or illness. These individuals normally present to the doctor or the nurse in the belief that the professional can do something to help to make the individuals' experience or indeed their lives better. Gordon Allport argued ${ }^{22}$ that each person is like every other person, like some other people, like no other person. Each of us contains within us both general patterns and the particular, that which is peculiar to me and my context.

\section{Contribution of the arts}

The arts, particularly literature, may contribute here in at least three separate, but inter-linked, ways. The arts may stimulate: (a) insight into common patterns of response (common or shared human experience); (b) insight into individual difference or uniqueness, and/or (c) enrichment of language and thought.

(A) INSIGHT INTO COMMON PATTERNS OF RESPONSE A work of art potentially provides one with sufficient imaginative insight to recognise general patterns of emotion and human response, which are not reducible to purely physical, biological mechanisms. Therefore while literature provides us with rich characterisation which can provide role models, it also appeals to something akin to the Jungian collective unconscious, to the archetypal stories of human existence. As Gardner argues: "Art rediscovers, generation by generation, what is necessary to humanness". ${ }^{23}$

Therefore it is not simply the case that science, medical science included, forces one to focus on general patterns of disease, behaviours and response, while the arts force us to focus on the particular. Literature also includes some image of the general, some often strong image of that which we share as human beings; some insight into the human condition as such-otherwise one would have difficulty relating to much literature and works of art. I believe I disagree with Downie on this last point. Downie's focus is exclusively on the particular, which he argues gives "whole person understanding". He suggests that to argue that literature can do more, within this context, is merely to fall into the danger of being accused of suggesting that the arts do badly what science does well. Yet he does in passing state the following: "Whereas science, including social science, proceeds by induction from specific instances to generalised (often idealised) patterns, literature explores unique situations which may include conflict of values. It thereby enables us to acquire insights into universal human predicaments." 17

I am challenged at this point to consider the difference between Downie's specific instances of 
inductive thought and the unique situations which he suggests leads to insight into aspects of "universal human predicaments". Are exploration and insight solely confined to the arts, and is induction the preserve of science? Scientists such as Ian Fleming or the astronomer Jocelyn Bell may well recognise more of the artistic in scientific discovery than Downie's analysis would suggest. I think perhaps a more accurate suggestion is that the arts do differently that which science sometimes does well. If one considers medical science or human sciences in general-psychology, sociology and so forth-all of these sciences are concerned with human behaviour and/or experience. Is this a subject matter different from that which concerns the artist? The contrasting notion that the arts do badly that which science does well would seem to be based on a mistaken assumption that what is of interest regarding human perception, emotion, awareness and response is entirely individualistic, utterly unique and particular. However, it may be useful to use a piece of literature to challenge this stance. Reflect for a moment on one's response to the following passage from John Bayley's account of trying to cope with his wife, the late Iris Murdoch, while she suffered Alzheimer's disease.

"The agony of travel nowadays. ... I am fumbling in my wallet, checking the tickets. They are hard to separate, and after shuffling them wildly again and again I can still find only one return ticket. The whole system is absurd; why must they give us four separate tickets when two would do? It's definitely not there. I rush to the ticket office, where a queue is made to unwind in serpentine fashion between rope barriers. My ticket man has drawn his little curtain and gone off. The customer at the other guichet seemed to want a round the world ticket, and to be in no hurry about getting it. $\mathrm{He}$ and the ticket clerk canvass the possibilities in leisurely fashion. Iris clutches me anxiously, urging us to run to a train which has just come in, the wrong train I hope. At last the ticket man is free. I produce the receipt and the delinquent tickets. No, he can do nothing-it wasn't his sale. I turn away in despair. Why can't we just go home?

"Iris has not understood the problem and keeps urging me towards the wrong train. ...

"On the train I keep counting the tickets. The elderly couple opposite look sympathetically at Iris. I am clearly the one who's become a problem.

"Utterly exhausted and drenched in sweat. Vague heart sensations too. And the whole thing so trivial." ${ }^{24}$
Personally this passage stimulates a vivid enteric sympathy based on memories of similar personal struggles to retain control in public - amidst toddler, baby, buggy, and bags in busy train and underground stations, with awkward narrow turnstiles, jostling crowds, bewildered children and personal isolation. Neither experience, Bayley's nor mine, is entirely unique; each is at least partially an image of a common human sense of personal isolation and powerlessness.

\section{(B) INSIGHT INTO INDIVIDUAL DIFFERENCE/} UNIQUENESS

The second way in which the arts may contribute is by providing detailed insight into the lives and concerns of others. Thus exposure to the arts may help produce a tolerance for ambiguity and individual difference.

Downie suggests that:

"We learn from literature by imaginative identification with the situations or characters in literature, and by having our imaginations stretched through being made to enter into unfamiliar situations or to see points of view other than our own. Learning of this kind is generative of a deep understanding which is essential to humane doctoring." 25

Why then is this deeper understanding essential to humane practice? I have argued elsewhere ${ }^{26}$ that the answer to this question is connected to issues of role enactment and moral strategy. Imaginative identification or, as I term it, activity of the moral imagination is essential to good health care practice. It is activity of the moral imagination that enables the practitioner to connect with a patient at the level of human understanding and compassion. This understanding and compassion is a necessary element in humane nursing or medical practice.

An important relationship between art and nursing or medicine is therefore one that enables the moral imagination of the practitioner to be stimulated and developed in such a manner that sensitive, compassionate, constructive care is the likely result. Alzheimer's disease or herpes encephalitis are clear examples of the humanly devastating conditions the diagnosis and treatment of which highlight the importance of rigorous scientific investigation. Such investigation seems fundamental to any attempt to find a treatment for (or means of preventing) the human misery and loss wrought by these conditions which attack a human life and produce physical evidence of destruction and atrophy in the cerebral cortex. How this brain destruction is connected with the changes of human personality and intellect is little 
understood, except we know that human memory is crucially involved. How these conditions are experienced by sufferers is also little understood, though there is mounting evidence of the distress, fear and anxiety which may exist in both sufferers and their loved ones.

"There are so many doubts and illusions and concealments in any close relationship. Even in our present situation they can come as an unexpected shock. Her tears sometimes seem to signify a whole inner world which Iris is determined to keep from me and shield me from. There is something ghastly in the feeling of relief that this can't be so: yet the illusion of such an inner world still there-if it is an illusion-can't help haunting me." 27

Bayley goes on aptly to describe the problem for medicine as science and art:

"Showing me a tracing from the most elaborate of the brain scans Iris underwent a year or so ago, the doctor indicated the area of atrophy at the top. The doctors were pleased by the clearness of the indication. I thought then - the old foolish idea of the amazon - that her brainworld had lost its unknown mysteries, all the hidden life that had gone on in it. It had been there, physically and geographically there. And now it had proved to be empty. The grey substance that sustained its mysteries had ceased to function, whatever a 'function', in there, can possibly mean.

"Twice Iris had said to Peter Conradi that she feels now that she is 'sailing into darkness'... It seems to convey a terrible lucidity about what was going on. But can one be conscious in such a way without possessing the consciousness that can produce such language? If consciousness can go on producing such words, why not more, equally lucid?

"Were I an expert on the brain I should find it hard to believe in such flashes of lucidity revealing, as it were, a whole silent but conscious and watching world. It would be as if - to use a clumsy analogy from my hidden city in the jungle - a flash of lightning were to reveal its existence, and then the explorers found that it didn't exist after all.

"The words which Iris used with such naturalness and brilliance cannot be stacked there silently, sending out an occasional signal. Or can they?"28

Medicine as scientific practice needs to seek understanding of the degenerative, destructive physiological processes at work, in order to try to prevent, ameliorate or relieve the symptoms. Medicine as art needs to recognise the human being who is experiencing the symptoms, which particular symptoms the individual is experiencing and what that experience is like for this particular individual, in order to ensure that prescription is accurate, acceptable and likely to be complied with.

\section{(c) THOUGHT AND LANGUAGE}

A further aspect of the contribution that the arts, particularly literature, makes to health care practice is that literature enriches the language and thus the thought processes of practitioners; in a manner which provides a wealth of concepts and ideas with which to think about and conceptualise patient care. This is in fact illustrated in the short passage quoted above from Bayley's memoir to Iris Murdoch-for example the image of "sailing into darkness". This notion of the importance of language and the connections between the language we use and the manner in which we think has long occupied scholars in a number of disciplines from cognitive developmental psychology to moral philosophy.

In the area of moral philosophy, the late Iris Murdoch herself ${ }^{29}$ and the philosopher Cora Diamond $^{30}$ have, among others, argued that we are suffering from a vocabulary so reduced in the relevant concepts that it cannot support appropriate discussion of the moral problems and crises which confront human beings.

Having a sufficiently rich vocabulary to support a language of patient care is, I believe, profoundly important. This is because of the as yet poorly understood connection between thought and language. That thought and language are connected is undeniable. How that connection works is another question. As the Russian psychologist Vygotsky states: "Thought undergoes many changes as it turns into speech. It does not merely find expression in speech; it finds reality and form. ${ }^{\text {}} 1$

In a similar vein the philosopher of education P H Hirst reminds us: "In so far then as we can meaningfully be said to think in anything-we think in words". ${ }^{32}$ We need many words to think beyond demyelination or dysfunctional neurotransmitters to begin to appreciate the human being, experience and triumphs of our patients.

In terms of patient care I suggest that one of the most useful assignments to set students who have just covered the pathophysiology of a chronic debilitating illness is to read Kafka's Metamorphosis, ${ }^{33}$ or, for the student of depressive illness, Janice Galloway's The Trick is to Keep Breathing. ${ }^{34}$ 


\section{Conclusion}

There are numerous works of literature which provide rich characterisation and role models as food for the spirit, and stimulus to the moral imagination. There are also numerous works which provide, sometimes ironically, insight into the practitioner-patient relationship and indeed into the human condition. Good literature will also enrich our language with words, concepts and visions of human existence. This I believe summarises the relationship between the arts and medicine.

"True art is moral: it seeks to improve life and not debase it. It seeks to hold off, at least for a while, the twilight of the gods and us!"35

Is this not also the goal of nursing and medicine?

$M$ Therese Southgate-physician and former deputy editor of the fournal of the American Medical Association may usefully have the final word:

"Medicine and art have a common goal: to complete what nature cannot bring to a finish ... to reach the ideal ... to heal creation. This is done by paying attention. The physician attends the patient; the artist attends nature ... . . If we are attentive in looking, in listening and in waiting, then sooner or later something in the depths of ourselves will respond. Art, like medicine, is not an arrival; it's a search. This is why, perhaps, we call medicine itself an art." ${ }^{36}$

P Anne Scott, RGN, BA(Hons), MSc, PhD, is Senior Lecturer, Department of Nursing and Midwifery, University of Stirling, Stirling FK9 4LA.

\section{References}

Downie RS. Literature and medicine. Fournal of Medical Ethic 1991;17:93-6, 98.

2 Boyd KM, ed. The Pond Report. Report of a working party on the teaching of medical ethics. London: IME Publications, 1987.

3 United Kingdom Central Committee for Nursing and Health Visiting. Project 2000: a new preparation for nursing, midwifery and health visiting. London: UKCC, 1986.

4 Whose life is it anyway? A John Badham Film, based on the stage play, Whose life is it anyway? by Brian Clark. Los Angeles: MGM production, 1989.
5 Bennett A. Untold stories London Review of Books 1999;21,19: 11-16.

6 Lanara VA. Heroism as a nursing value: a philosophical perspective [2nd ed]. Athens: G Paponikolaon SA, 1996.

7 Cassell EJ. The place of the humanities in medicine. Hasting-onHudson, New York: The Hastings Centre, 1984.

8 See reference 7:167.

9 General Medical Council. Tomorrows's doctorsrecommendations on undergraduate medical education. London: General Medical Council, 1993.

10 Darbyshire P. Understanding caring through arts and humanities: a medical/nursing humanities approach to promoting alternative experiences of thinking and learning. Fournal of Advanced Nursing 1994;19:856-63.

11 Passionfish. A John Sales Film. Los Angeles: Miramax Productions, 1992.

12 Szasz TS, Hollander MH. The basic models of the doctor patient relationship. Archives of Internal Medicine 1956;97:585.

13 Veatch RM. Models for ethical medicine in a revolutionary age. The Hastings Centre Report 1972;3:3.

14 Morse JM Negotiating commitment and involvement in the nurse-patient relationship. fournal of Advanced Nursing, 1991; 16,4:455-68

15 Greenhaugh T, Hurwitz B. Why study narrative? In: Greenhaugh T, Hurwitz B, eds. Narrative based medicine: dialogue and discourse in clinical practice. London: BMJ Books, 1998: 3-16.

16 Phillips DC. Holistic thought in social science. California: Stanford University Press, 1977.

17 See reference 1: 95

18 Ford P, Walsh M. New rituals for old: nursing through the looking glass. Oxford: Butterworth Heinemann, 1994.

19 Melia KM. Learning and working: the occupational socialisation of nurses. London: Tavistock Publications Ltd, 1987.

20 Madjar I, Walton JA, eds. Nursing and the experience of illness: phenomenology in practice. London: Routledge, 1999.

21 Benner P, ed. Interprepretive phenomenology. New York: Sage, 1994.

22 Allport G. Becoming: basic considerations for a psychology of personality. New Haven: Yale University Press, 1955

23 Gardner J. On moral fiction. New York: Basic Books/Harper Collins, 1978.

24 Bayley J. Iris: a memoir of Iris Murdoch. London: Duckworth, 1998.

25 See reference 1: 96

26 Scott PA. Imagination in practice. Fournal of Medical Ethics 1997; 23,1:45-50

27 See reference $24: 178$

28 See reference $24: 179$

29 Murdoch I. Metaphysics as a guide to morals. London: Chatto and Windus Ltd, 1992

30 Diamond C. Losing your concepts. Ethics 1988;98:255-77.

31 Vygotsky L. Thought and language. [Translated by Alex Kozulin]. Massachusetts: MIT Press, 1986.

32 Hirst PH. Knowledge and the curriculum. London: Routledge \& Kegan Paul, 1974.

33 Kafka F. Metamorphosis and other stories. [Translated by Willa and Edwun Muir]. London: Minerva, 1992.

34 Galloway J. The trick is to keep breathing. London: Minerva, 1989.

35 See reference 23:5.

36 Southgate MT, Quoted in Downie RS, ed. The healing arts. Oxford: Oxford University Press, 1994: xvii. 